\title{
Secondary postpartum hemorrhage on day 58 of cesarean section due to uterine scar rupture
}

\author{
Yogita B. Gavit*, Deepika Sharma
}

Department of Obstetrics and Gynecology, Lokmanaya Tilak Government Medical College, Mumbai, Maharashtra, India

Received: 04 September 2020

Accepted: 07 October 2020

*Correspondence:

Dr. Yogita B. Gavit,

E-mail: Dryogita1990@gmail.com

Copyright: (c) the author(s), publisher and licensee Medip Academy. This is an open-access article distributed under the terms of the Creative Commons Attribution Non-Commercial License, which permits unrestricted non-commercial use, distribution, and reproduction in any medium, provided the original work is properly cited.

\begin{abstract}
Secondary postpartum hemorrhage is rare and affect $0.23-3 \%$ of all pregnancies. It happens between 24 hours to 12 weeks of post-delivery. These postpartum hemorrhages occur more often during normal vaginal delivery only a small subset of postpartum hemorrhages occurs after cesarean section. Delayed postpartum hemorrhage is obstetrics emergencies that occurs following vaginal or cesarean delivery, in later condition may be caused by dehiscence of uterus incision after cesarean section which can lead to severe and fatal bleeding. We herein report a case of secondary postpartum hemorrhage after cesarean section.
\end{abstract}

Keywords: Secondary postpartum hemorrhage, Uterine scar rupture, Dehiscence

\section{INTRODUCTION}

Postpartum is an obstetrics emergency that occurs following vaginal or caesarean delivery major cause of postpartum hysterectomy and maternal mortality. Secondary postpartum hemorrhage is defined as excessive vaginal bleeding in the period from 24 hours after delivery to 12 weeks postpartum. ${ }^{1,2}$ According to World Health Organization (WHO), postpartum hemorrhage is responsible for about $25 \%$ of all maternal death. ${ }^{3}$ Secondary postpartum hemorrhage most common cause is placental regression 4 after cesarean section is rare and occurs in $1 / 3654 .{ }^{4}$ It is characterized by severe bleeding, shock or anemia therefore proper diagnosis and management of bleeding is crucial, depending on severity and extent of bleeding pharmacological, mechanical, surgical intervention may be applicable. ${ }^{4,5}$ Secondary postpartum hemorrhage and delayed bleeding can occur after dehiscence of uterus incision after cesarean section.

\section{CASE REPORT}

Mrs. XYZ 25 Year old Para1living1 with day 58 Lower segment cesarean section (LSCS) was referred from Thane
Municipal Hospital in view of secondary postpartum hemorrhage, patient gave history of per vagina bleeding since 5 hours, soakage 7-8 pads with no passage of clots, no history of fever, chills, rigors, discharge from wound site, hypertension, Diabetes mellitus (DM), asthma, tuberculosis, epilepsy, thyroid disorder. Cesarean section done in Thane Municipal Hospital, LSCS done in view of non-progress of labour, post-operative uneventful. Patient went to Thane Municipal Hospital with similar complaint at 38 day of LSCS for which she received 2 pint of pack cell volume and referred to Lokmanaya Tilak medical college, Sion for further management, patient came to Sion hospital in labor room on 38th day of LSCS.

\section{On examination}

General condition: fair, conscious oriented, pallor present grade 3 afebrile, pulse rate: 96 bpm low volume, blood pressure 110/70 $\mathrm{mmHg}$. Cardiovascular system: S1S2 present , respiratory system: air entry equal on both sides, per abdomen: soft, no guarding/rigidity/tenderness, uterus 12 weeks, well retracted, wound site healthy, per speculum: active bleeding present but cervix and vaginal healthy, per vagina: uterus 12 weeks size, bilateral fornix 
clear no tender, OS closed, bleeding present, blood investigation done: hemoglobin $7 \mathrm{gm} \%$, white blood cells (WBC) $28000 \mathrm{cmm}$, platelet 2,46,000 $\mathrm{cmm}$, liver and kidney function test normal, blood culture no growth detected. High vaginal swab: no growth detected. Urine routine: no pus cells, report normal. Ultrasound abdomen and pelvis: no abnormality detected. Diagnosis: P1L1 with day 38 LSCS with secondary postpartum hemorrhage. Patient treated with intravenous antibiotics- injection piperacillin $4.45 \mathrm{gm} 12$ hourly, injection metronidazole $400 \mathrm{mg} 12$ hourly for 7 days rest supportive medication like antacid, intravenous fluids.

Patient recovered on discharge no active bleeding, hemogram within normal limits. Advised oral hematinic.

On day 58 of LSCS patient came with complain of per vagina bleeding, giddiness, breathlessness since 5 hours. No history of fever, chills, rigors.

\section{On examination}

General condition: moderate, afebrile, conscious oriented, pallor grade 4 present. Pulse rate: $110 \mathrm{bpm}$ low volume, blood pressure $90 / 70 \mathrm{mmHg}$, respiratory rate: $28 /$ minute, cardiovascular system : S1S2 present, respiratory system: air entry equal on both sides, per abdomen: soft, no guarding/rigidity/tenderness, uterus 12 weeks, well retracted, wound site healthy, per speculum: active bleeding present, per vagina: uterus 12 weeks size, cervix not palpable.

Blood investigations done: hemoglobin $5 \mathrm{gm} \%$, WBC $9000 \mathrm{cmm}$, platelet 2,58,000 cmm, Prothrombin time/ International normalized ratio (PT/INR) 16/1.8, total bilirubin $0.6, \quad$ Serum glutamic-oxaloacetic transaminase/Serum glutamic-pyruvic transaminase, (SGOT/SGPT) 12/17, arterial blood gas with electrolytes: normal. Patient was immediately taken for exploratory laparotomy under general anesthesia with blood and blood products in hand. Intra operative findings: no evidence of hemoperitoneum, uterus size $10 \times 8 \times 9 \mathrm{~cm}$, uterine scar rupture full length; edges of scar healthy; bleeder noted on right uterine angle which was liagated with vicryl number 1. Uterine scar sutured with chromic catgut number 2 in continuous interlocking single layer, bilateral internal iliac artery ligation done prophylactically. Homeostasis was achieved, abdominal drained kept. Intra operatively 2-pint pack cell volume and 4-pint fresh frozen plasma transfused.

Post operatively patient was shifted to surgical intensive care unit for monitoring, intravenous antibiotics started injection piperacillin 4.45 gms 12 hourly, injection metronidazole $400 \mathrm{mg} 12$ hourly, with antiemetic for 7 days followed by oral antibiotics for 7 days and intravenous fluids for 2 days till patient was nil by mouth. Post-operatively 4-pint pack cell volume transfused, uneventful. On day 5 of laparotomy abdominal drained removed, on day 12 sutures removed wound healthy, on day 13 patient was discharged.

Table 1: Investigation table.

\begin{tabular}{|lllllll|}
$\begin{array}{l}\text { Day of } \\
\text { LSCS }\end{array}$ & $\mathbf{3 8}^{\text {th }}$ & $\mathbf{4 6}^{\text {th }}$ & $\mathbf{5 9}^{\text {th }}$ & $\mathbf{6}^{\text {th }}$ & $\mathbf{6}^{\text {th }}$ & $\mathbf{6 7}^{\text {th }}$ \\
\hline Hb \% & 7.0 & 9.0 & 6.0 & 7.5 & 8.8 & 9 \\
\hline WBC & 280 & 120 & 670 & 700 & 720 & 700 \\
& 00 & 00 & 0 & 0 & 0 & 0 \\
\hline Platelet & 246 & 248 & 250 & 252 & 249 & 248 \\
BUN/Cre & 1000 & 000 & 000 & 000 & 000 & 000 \\
atinine & .8 & 8 & .8 & .8 & .7 & .7 \\
\hline PT/INR & $16 / 1$ & $16 / 1$ & $18 / 2$ & $17 / 1$ & $16 / 1$ & $16 / 1$ \\
\hline Total & .0 & .0 & .0 & .5 & .3 & .0 \\
bilirubin & 0.6 & 0.6 & 0.6 & 0.6 & 0.7 & 0.6 \\
\hline SGOT/S & $15 / 1$ & $16 / 1$ & $22 / 1$ & $17 / 1$ & $18 / 2$ & $20 / 2$ \\
GPT & 8 & 8 & 8 & 8 & 0 & 2 \\
\hline RBS & 98 & 99 & 90 & 105 & 109 & 110 \\
\hline Na $/$ K & $144 /$ & $139 /$ & $144 /$ & $140 /$ & $144 /$ & $138 /$ \\
\hline
\end{tabular}

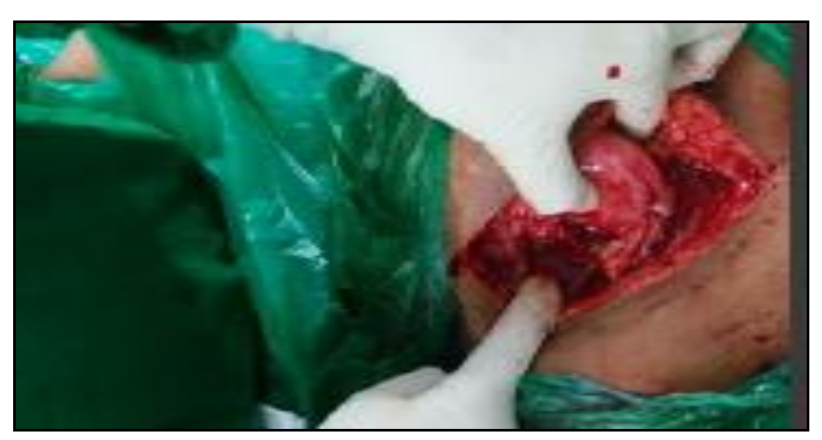

Figure 1: Intra-operative image (full length uterine scare rupture).

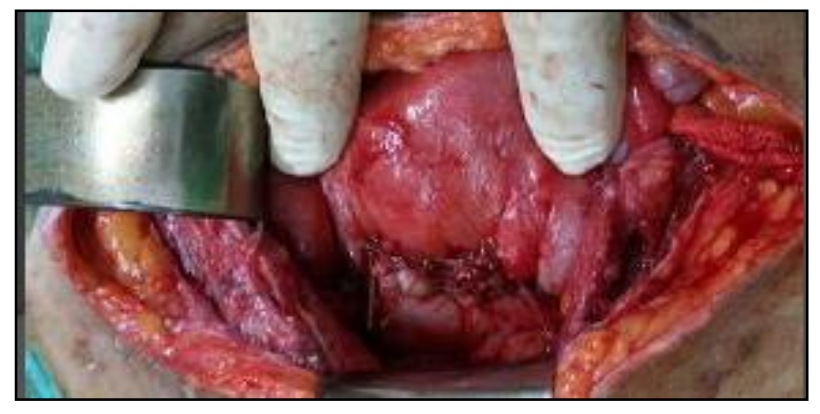

Figure 2: Post-operative image (sutured with chromic catgut number 1 ).

\section{DISCUSSION}

Incidence of uterine scar dehiscence irrespective of the cause is around $0.6 \%$ worldwide. ${ }^{4,5}$ Typical important cause would be previous lower segment cesarean section, classical cesarean section, previous uterine trauma, congenital anomaly, abnormal placentation and 
inappropriate oxytocin administration. The timing of spontaneous cesarean uterine wound dehiscence or rupture usually occurs during pregnancy or labor in a scarred uterus. By contrast postpartum cesarean uterine wound dehiscence is very rare. ${ }^{6,7,8}$ Although uncommon, postpartum cesarean uterine wound dehiscence is life threatening. According to previous reports, postpartum cesarean uterine wound dehiscence tends to occur in scarred uterus with coincident infection such as chorioamnionitis, endometritis, and abscess formation. ${ }^{9}$ In these reports, abdominal pain and fever are common symptoms. However, in our case patient presented with per vagina bleeding and hypovolemic shock only. No obvious abdominal pain or infection signs were noted. Exploratory laparotomy should be considered as the most important tool of diagnosis and treatment for uterine scar rupture and repair. Conservative resuturing and debridement can be chosen, but in presence of marked wound infection, endomyometritis, intra-abdominal abscess hysterectomy should be considered.

\section{CONCLUSION}

Secondary postpartum hemorrhage is important cause of maternal morbidity and mortality. Basic resuscitation followed investigation and treatment of specific cause of hemorrhage are essential. Exploratory laparotomy should be considered as the most important tool for diagnosis and treatment of uterine scar rupture which should be suspected in cases of secondary postpartum hemorrhage and repaired. Conservative resuturing after debridement can be chosen, but in presence f marked wound infection, endomyometritis intra-abdominal abscess hysterectomy should be considered.

Funding: No funding sources Conflict of interest: None declared

Ethical approval: Not required

\section{REFERENCES}

1. Comittee on Practice Bulletins-Obstetrics Practice Bulletin No 183: Postpartum Hemorrhage. Obstet Gynecol 2017;130:e168.

2. Dossoum M, Debost-Legrand A, Dechellotte P. Severe Secondary Postpartum hemorrhage: a historical cohort. Birth. 2015;42:149.

3. WHO Recommendations for prevention and Treatment of Postpartum Hemorrhage. World health Organization, Geneva. 2012. Accessed on 02 July, 2020.

4. Wagner MS, Bedard MJ. Postpartum uterine dehiscence: a case report. J Obstet Gynaecol Can. 2006;28(8):713-5.

5. Combs CA. Murphy EL, LarosJR. Factors associated with postpartum hemorrhage with vaginal birth. Obstet Gynecol. 1991;77(1):69-76.

6. Guiheneuf A. Cabaret AS, Grall JY. A case of uterine rupture discovered in the postpartum period. J Gynecol Obstet Biol Reprod. 2008:37197e9.

7. Musa J, Misauno MA. Uterine rupture in primigravida presenting as acute abdomen post delivery: a case report. Niger J Med. 2007;16:274e6.

8. Waseem M, Cunningham-Deshong H, Gernsheimer J. Abdminal pain in a postpartum patient. J Emerd Med. 2011;41:261e4.

Cite this article as: Gavit YB, Sharma D. Secondary postpartum hemorrhage on day 58 of cesarean section due to uterine scar rupture. Int J Reprod Contracept Obstet Gynecol 2020;9:4762-4. 